\title{
Multilocus Genotypes of the Wheat Leaf Rust Fungus Puccinia triticina in Worldwide Regions Indicate Past and Current Long-Distance Migration
}

\author{
J. A. Kolmer, ${ }^{1, \dagger}$ M. E. Ordoñez, ${ }^{2}$ S. German, ${ }^{3}$ A. Morgounov, ${ }^{4}$ Z. Pretorius, ${ }^{5}$ B. Visser, ${ }^{5}$ \\ H. Goyeau, ${ }^{6}$ Y. Anikster, ${ }^{7}$ and M. Acevedo ${ }^{8}$ \\ ${ }^{1}$ Cereal Disease Laboratory, United States Department of Agriculture, St. Paul, MN 55108, U.S.A. \\ ${ }^{2}$ Pontificia Universidad Catolica del Ecuador, Quito, Ecuador \\ ${ }^{3}$ Instituto Nacional de Investigación Agropecuaria (INIA), Estación Experimental INIA La Estanzuela, 39173 Colonia, Uruguay \\ ${ }^{4}$ International Wheat and Maize Improvement Center, 06511 Ankara, Turkey \\ ${ }^{5}$ Faculty of Natural and Agricultural Sciences, University of the Free State, Bloemfontein, South Africa \\ ${ }^{6}$ National Institute for Agricultural Research, Bioger-CPP, 78850 Thiverval-Grignon, France \\ ${ }^{7}$ Institute for Cereal Crop Improvement, Tel Aviv University, Tel Aviv 69978, Israel \\ ${ }^{8}$ International Programs-CALS, Cornell University, Ithaca, NY 14853, U.S.A. \\ Accepted for publication 25 March 2019.
}

\begin{abstract}
Many plant pathogenic fungi have a global distribution across diverse ecological zones and agricultural production systems. Puccinia triticina, the wheat leaf rust fungus, is a major pathogen in many wheat production areas of the world. The objective of this research was to determine the genetic relatedness of $P$. triticina in different worldwide regions. A total of 831 single-uredinial isolates collected from 11 regions were characterized for multilocus genotype at 23 simple sequence repeat loci and for virulence to 20 lines of wheat with single genes for leaf rust resistance. A total of 424 multilocus genotypes and 497 virulence phenotypes were found. All populations had high heterozygosity and

significant correlation between virulence and molecular variation, which indicated clonal reproduction. The populations from North America and South America, Central Asia and Russia, and the Middle East and Europe were closely related for multilocus genotypes and many individual isolates from other continental regions were closely related. Twenty-seven multilocus genotypes were found in more than one continental region, and 13 of these had isolates with identical virulence phenotypes. The wide geographic distribution of identical and highly related multilocus genotypes of $P$. triticina indicated past and more recent migration events facilitated by the spread of clonally produced urediniospores.
\end{abstract}

Many important plant pathogens and pests are widespread throughout the major agricultural and ecological regions of the world. Plant pathogenic fungi in particular are distributed across different continents and are rarely endemic to only one country or continental region (Bebber et al. 2014). Although fungi have the narrowest host range of various pathogens and pests, they have the highest saturation rate (the number of countries where the pathogen or pest was found/the number of countries where the pathogen or pest could be present based on host population) compared with other pathogens and insect pests. Among crop pathogens and pests, fungal pathogens have the lowest rate of regional endemicity at $5.8 \%$ and are the leading category of global plant pathogen invaders (Bebber et al. 2014).

The wide distribution is evidence of the ability of fungal plant pathogens to adapt to natural host environments (Gladieux et al. 2015) and also to exploit the genetic uniformity of many host populations in human-guided agricultural production systems. Fungal pathogens have achieved this in various ways, depending on their means of dispersal. Pathogen distribution is affected by human activities, as in the case of Cryphonectria parasitica, the chestnut blight fungus, and Ophiostoma ulmi, the Dutch elm disease fungus, both of which were introduced to North America in the last century

${ }^{\dagger}$ Corresponding author: J. A. Kolmer; jim.kolmer@ars.usda.gov

*The $\boldsymbol{e}$-Xtra logo stands for "electronic extra" and indicates that two supplementary figures and four supplementary tables are published online.

The author(s) declare no conflict of interest.

This article is in the public domain and not copyrightable. It may be freely reprinted with customary crediting of the source. The American Phytopathological Society, 2019. by transport of infected plant material from Europe (Brown and Hovmøller 2002). Other types of fungal pathogens, such as rust fungi, have infective spores that are adapted for wind dissemination over thousands of kilometers (Kolmer 2005; Visser et al. 2019), in addition to being transported over long distances by human activities (Park et al. 1995; Steele et al. 2001).

Puccinia triticina Erikss., the wheat leaf rust fungus, is found throughout most of the nonarid wheat production areas of the world (Roelfs et al. 1992; Saari and Prescott 1985; Samborski 1985). The principal uredinial-telial hosts are hexaploid common wheat (Triticum aestivum L.), tetraploid durum wheat (T. turgidum L.), and wild emmer wheat (T. dicoccoides L.) (Bolton et al. 2008). Clonal reproduction of urediniospores occurs on the uredinial-telial hosts. Since $P$. triticina is a heteroecious rust, an alternate host is required for completion of the sexual cycle. The native habitat of the most compatible alternate host (pycnial-aecial spore stages), Thalictrum speciosissimum L., is limited to southern Europe (Casulli 1988; Casulli and Siniscalco 1987; Sibilia et al. 1963; Tommasi et al. 1980) and parts of West Asia (Tatlidil et al. 2005).

Individual populations of $P$. triticina have been examined for molecular variation and virulence in numerous studies. Annual virulence surveys of $P$. triticina are conducted in the United States (Kolmer and Hughes 2017) and Canada (McCallum and Seto-Goh 2006), which provide immediate information to help inform and support breeding programs in the selection of resistant wheat germplasm. Although there is considerable knowledge regarding genetic variation within different continental regions, no previous study has examined the genetic relationship and diversity of P. triticina populations between different continental regions. At the U.S. Department of Agriculture Agricultural Research Service (USDA-ARS) Cereal Disease Laboratory, P. triticina populations from North America (Ordoñez and Kolmer 2009), South America 
(Ordoñez et al. 2010), the Middle East (Kolmer et al. 2011), Central Asia (Kolmer and Ordoñez 2007), Europe (Kolmer et al. 2012), Russia (Kolmer et al. 2015), China (Kolmer 2015), East Africa (Kolmer and Acevedo 2016), and Pakistan (Kolmer et al. 2017) were examined for virulence to a standard set of wheat differential lines and for multilocus genotype (MLG) using a standard set of simple sequence repeat (SSR) markers. The objective of this study was to determine the genetic relatedness among these P. triticina populations. We also wished to determine whether MLGs and virulence phenotypes of $P$. triticina are closely associated with geographic regions or if individual isolates from different continents are highly related for both SSR variation and virulence, which would support the hypothesis of migration of clonal urediniospores between continental regions.

\section{MATERIALS AND METHODS}

Isolates of $\boldsymbol{P}$. triticina. Isolates of $P$. triticina were obtained from field surveys and collections held in national laboratories in North America, South America, the Middle East, Central Asia, Europe, East Africa, Russia, China, and Pakistan (Supplementary Table S1). Collections were made from both common hexaploid wheat and from tetraploid durum wheat. Additional field collections were obtained from New Zealand in the mid-1990s, while isolates from South Africa were obtained in the mid-1990s and in 2012. All collections and isolates were purified by increasing urediniospores taken from a single uredinium on susceptible wheat seedlings in isolation chambers in a greenhouse (Kolmer and Hughes 2017). All single-uredinial isolates were assessed for seedling virulence to a set of 20 Thatcher wheat lines that are near isogenic for the following single leaf rust resistance genes: $\operatorname{Lrl}$, Lr2a, Lr2c, Lr3, Lr9, Lr16, Lr24, Lr26, Lr3ka, Lr11, Lr17, Lr30, LrB, Lr10, Lr14a, Lr18, Lr3bg, Lr14b, Lr20, Lr28, and Thatcher as a susceptible control. The procedures and greenhouse conditions were as previously described (Kolmer and Hughes 2017; Ordoñez and Kolmer 2009). The isolates were rated for virulence to the individual Thatcher differential lines 10 to 12 days after inoculation. Isolates with infection types 3 and 4 (moderate to large uredinia lacking necrosis or chlorosis) were considered virulent, and infection types 0 to $2^{+}$(immune response with no sign of infection to moderate size uredinia with prominent chlorosis) were considered avirulent to the particular Thatcher line. The virulence phenotypes were described using a five-letter code, in which each letter described virulence or avirulence to four Thatcher differential lines (Supplementary Table S2), adapted from the hexadecimal nomenclature used to describe virulence in $P$. triticina (Long and Kolmer 1989). Each isolate was also given a 20-digit binary number based on the avirulent/virulent response to the Thatcher differential lines.

Molecular genotyping. DNA was extracted using the Omniprep kit (G-Biosciences) from at least one isolate of every virulence phenotype (or race) from each country or region in each of the continental populations. If multiple isolates with the same virulence designation were found in a country or region, DNA was extracted from at least two isolates of the same phenotype. All isolates were genotyped for allelic variation with a set of 23 SSR primers developed from genomic libraries of $P$. triticina. Primers Pt3, Pt13, Pt50, Pt55, Pt61, Pt68-1, Pt76-2, Pt91, Pt92, Pt138, Pt152, Pt154, Pt158, Pt161, Pt164, Pt173, Pt184, and Pt186 were developed by Szabo and Kolmer (2007), and primers Frl, Fr8, Fr11, Fr26, and Fr35 were developed by Duan et al. (2003). The PCR products were labeled with fluorescent primers and allele sizes in base pairs scored visually for each primer pair using a LI-COR 4200 or 4300 DNA sequencer with IRDye 700 molecular weight standards. Molecular weights for all alleles of each isolate were standardized with alleles from two isolates that were used as controls in all studies. All isolates were assigned an MLG number in GenAlex 6.502 (Peakall and Smouse 2012).
A total of $831 P$. triticina isolates from 11 regions were analyzed for various measures of genetic diversity, genetic distance, and differentiation. All populations were clone corrected, with only a single isolate for each virulence phenotype-MLG combination within each country or region in each population retained. Since different phenotypes could have identical MLGs, multiple isolates could have the same MLG within the same population, while the same phenotypes could have different MLGs.

Analysis of regional populations. The R-based program Poppr 2.02 (Kamvar et al. 2014) was used to determine the number of MLGs and the genetic distance between regional populations. An unrooted neighbor-joining dendrogram of Nei's genetic distance between regional populations was generated in the R-based program APE (Paradis et al. 2004) with 1,000 bootstrap samples. Values of $F_{S T}$ between the regional populations were determined with GenAlex. Allelic diversity (average number of alleles/locus, average number of effective alleles/locus), observed $\left(H_{o}\right)$ and expected $\left(H_{e}\right)$ heterozygosity, and the inbreeding coefficient $F_{I S}$ averaged over all loci for each population were determined with GenAlex. Minimum spanning trees of MLGs in the regional populations were generated in Poppr.

Analysis of MLG groups. In previous studies of $P$. triticina variation in individual regions (Kolmer 2015; Kolmer and Acevedo 2016; Kolmer and Ordoñez 2007; Kolmer et al. 2011, 2012, 2015, 2017; Ordoñez and Kolmer 2009; Ordoñez et al. 2010), a total of 40 MLG groups within the regional populations were determined using principal coordinate plots in GenAlex, Bayesian methods in Structure (Pritchard et al. 2000), and $k$ means clustering in Genodive version 2.0b27 (Meirmans and van Tienderen 2004). The number of MLGs, effective number of MLGs, and Simpson's unbiased $(\lambda)$ diversity for each MLG group were determined with Genodive. An unrooted neighbor-joining tree of Nei's genetic distance between the MLG groups was generated with APE with 1,000 bootstrap samples. Analysis of molecular variation (AMOVA) and values of $F_{S T}$ between the MLG groups were determined with GenAlex.

Values of $P_{\text {sex }}$ (Stenberg et al. 2003) for each MLG that occurred in more than one regional population were calculated with GenAlex. The relationship between the virulence phenotype of all of the isolates and their MLGs was determined by comparing the distance matrix of the 20-digit binary numbers with the genetic distance matrix of the MLGs, using the Mantel correlation coefficient in GenAlex. The correlation between MLG and virulence was also determined for the 11 regional populations individually.

\section{RESULTS}

A total of 172 alleles at the 23 SSR loci were used to genotype the $P$. triticina populations from 11 regions. Of the $831 P$. triticina isolates that were genotyped, there were a total of 424 MLGs. The 23 SSR loci were sufficient to detect variation in the $P$. triticina populations as the number of MLGs began to flatten out between 20 and 22 SSR loci (Supplementary Fig. S1) in the genotype accumulation curve. Fifty-eight MLGs were found in North America, 75 in South America, 81 in Europe, 47 in the Middle East, 21 in East Africa, 36 in Russia, 28 in Pakistan, 72 in Central Asia, 36 in China, 9 in New Zealand, and 11 in South Africa.

Regional MLG differentiation and genetic diversity. The isolates were initially grouped based on regions for measures of MLG genetic differentiation, diversity, and heterozygosity. All populations were significantly differentiated with $F_{S T}$ at $P<0.05$, and most pairs were significant at $P<0.001$ (Table 1). The populations from Russia and East Africa and from Russia and North America had the highest $F_{S T}$ values of 0.272 and 0.259 , respectively. The populations from South America and North America and from the Middle East and East Africa were the most closely related, with the lowest $F_{S T}$ values of 0.016 and 0.025 , respectively. The population from New Zealand, when paired with populations from 
South Africa, Pakistan, and the Middle East, was significantly differentiated from these populations at $P<0.05$ but not at lower probability levels. This was likely attributable to the small number of isolates $(n=10)$ in the New Zealand population. A larger sample size in the New Zealand population would have likely resulted in higher levels of $F_{S T}$ and lower probabilities as seen in the other population pairings.

The genetic relationship between the regional populations based on MLGs was also seen with Nei's genetic distance in an unrooted neighbor-joining tree (Fig. 1). The population pairs from North America and South America, the Middle East and East Africa, Pakistan and Europe, and Central Asia and Russia were closely related, with high bootstrap values. The populations from Russia and East Africa and from Russia and North America were the most distantly related.

In separate minimum spanning trees of the closely related population pairs, the MLGs were interspersed among each other, with little or no separation (Supplementary Fig. S2). Nine MLGs were in common in North America and South America, two in Europe and Pakistan, two in East Africa and the Middle East, and two in Russia and Central Asia.

The regional populations were also assessed for heterozygosity and allelic diversity in order to determine whether there were significant differences in the distribution of genetic diversity within the regions. Nine of the 11 populations had $F_{I S}$ values significantly less than zero, which indicated that these populations had significantly greater observed heterozygosity $\left(H_{o}\right)$ per locus compared with expected heterozygosity $\left(H_{e}\right)$ under Hardy-Weinberg equilibrium (Fig. 2A). Only the populations from East Africa and South Africa had nonsignificant values of $F_{I S}$. Significant negative values of $F_{I S}$ are considered to be indicators of clonal reproduction (Halkett et al. 2005), since they represent the deviation from random mating within populations in the absence of sexual recombination. The number of SSR alleles per locus in the regional populations ranged from 2.96 in South Africa to 4.96 in Europe (Fig. 2B). In all of the populations, the number of effective alleles per locus, which is the number of equally frequent alleles that would result in the same level of $H_{e}$, was significantly less than the actual number of alleles, which indicated an uneven distribution of alleles within each population. Taken together, the high levels of heterozygosity and the uneven distribution of alleles were indicators of deviations from random mating populations and of clonal reproduction in the regional populations.

Virulence phenotypes and MLG correlation. Among the isolates, a total of 497 virulence phenotypes were identified based on the avirulent/virulent responses to the 20 near-isogenic lines of Thatcher wheat. There were 89 virulence phenotypes in North America, 85 in South America, 106 in Europe, 77 in the Middle East, 22 in East Africa, 41 in Russia, 24 in Pakistan, 66 in Central Asia, 48 in China, eight in New Zealand, and 18 in South Africa. Nine Ethiopian isolates that were virulent to durum wheat had a low infection type of fleck to Thatcher wheat and could not be evaluated

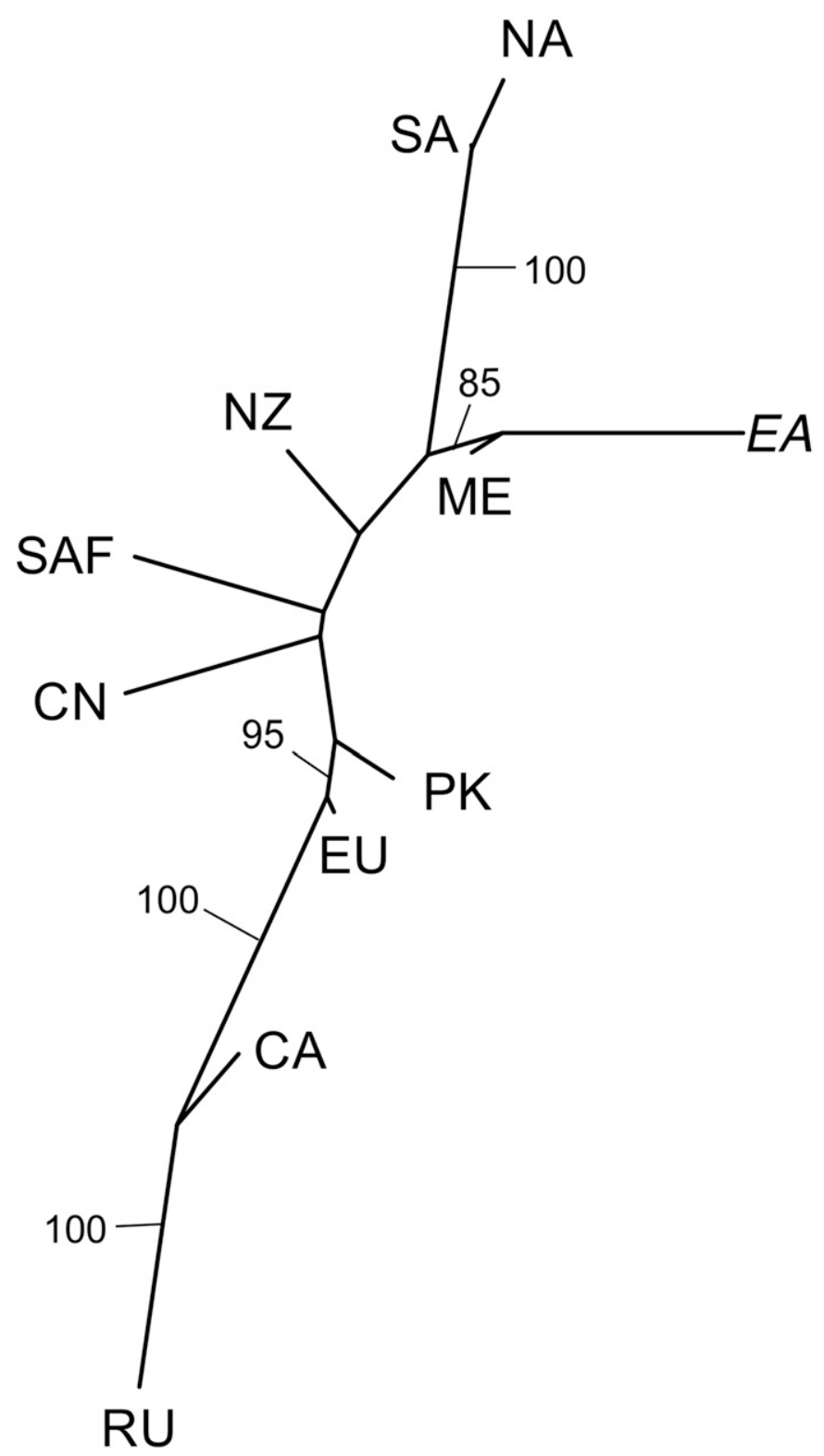

Fig. 1. Neighbor-joining plot of Nei's genetic distance of multilocus genotypes between Puccinia triticina isolates in 11 regional populations. The plot is based on 1,000 bootstrap samples with support values $>50 \%$ indicated at nodes. NA $=$ North America, $\mathrm{SA}=$ South America, $\mathrm{EA}=$ East Africa, $\mathrm{ME}=$ Middle East, $\mathrm{NZ}=$ New Zealand, $\mathrm{SAF}=$ South Africa, $\mathrm{CN}=$ China, $\mathrm{PK}=$ Pakistan, $\mathrm{EU}=$ Europe, $\mathrm{CA}=$ Central Asia, and RU = Russia.

TABLE 1. Estimates of genetic differentiation using $F_{S T}$ in 11 regional populations of Puccinia triticina based on multilocus genotypes at 23 microsatellite locia

\begin{tabular}{|c|c|c|c|c|c|c|c|c|c|c|c|}
\hline North America & Central Asia & New Zealand & South Africa & Russia & China & Pakistan & Europe & Middle East & South America & East Africa & Population \\
\hline 0.000 & & & & & & & & & & & North America \\
\hline $0.202 *$ & 0.000 & & & & & & & & & & Central Asia \\
\hline $0.088^{* *} *$ & $0.124 *$ & 0.000 & & & & & & & & & New Zealand \\
\hline $0.259^{*}$ & $0.043^{*}$ & $0.210^{*}$ & $0.187 *$ & 0.000 & & & & & & & Russia \\
\hline $0.135^{*}$ & $0.108 *$ & $0.056 * *$ & $0.069 *$ & $0.191 *$ & 0.000 & & & & & & China \\
\hline $0.120 *$ & $0.060 *$ & $0.055 * * *$ & $0.069 *$ & $0.148 *$ & $0.057 *$ & 0.000 & & & & & Pakistan \\
\hline $0.125^{*}$ & $0.051 *$ & $0.043 * *$ & $0.055^{*}$ & $0.121 *$ & $0.056 *$ & $0.026^{*}$ & 0.000 & & & & Europe \\
\hline $0.114 *$ & $0.179 *$ & $0.065^{* *}$ & $0.114 *$ & $0.272 *$ & $0.093 *$ & $0.074 *$ & $0.067 *$ & $0.025^{* *}$ & $0.105^{*}$ & 0.000 & East Africa \\
\hline
\end{tabular}

a Significant at $* P<0.001, * * P<0.01$, and $* * * P<0.05$. 
for virulence to the Thatcher differential lines. These isolates were given an EEEEE race designation. All other isolates from durum wheat were phenotyped on the Thatcher differentials. There was significant correlation between the MLGs and virulence phenotypes at the level of the individual isolates with no geographic grouping, isolates within regions, and isolates in different regions. When all 831 isolates were considered without any grouping, the Mantel correlation between MLGs and virulence phenotypes was $0.32(P<0.001)$. All regional populations had significant $(P<0.01)$ within correlation for MLG and virulence phenotypes from 0.32 for North America to 0.56 for Russia (Fig. 3). When the isolates were grouped by region, the Mantel correlation of Nei's genetic distance between populations for MLG and virulence phenotypes was
$0.64(P<0.002)$. The significant relationship between MLG and virulence was an additional indication of clonal reproduction in these populations.

MLG group diversity and differentiation. There were a total of 40 MLG groups from the previous studies of the individual regional populations, with six groups in North America (NA), five in South America (SA), eight in Europe (EU), three in the Middle East (ME), four in East Africa (EA), two in Russia (RU), three in Pakistan (PK), four in Central Asia (CA), and three groups in China (CN) (Table 2). Isolates from New Zealand (NZ) and South Africa (SAF) were each placed into one group each, as a result of the small number of isolates in these regions. MLG groups of isolates with virulence to durum wheat from North America, South America,
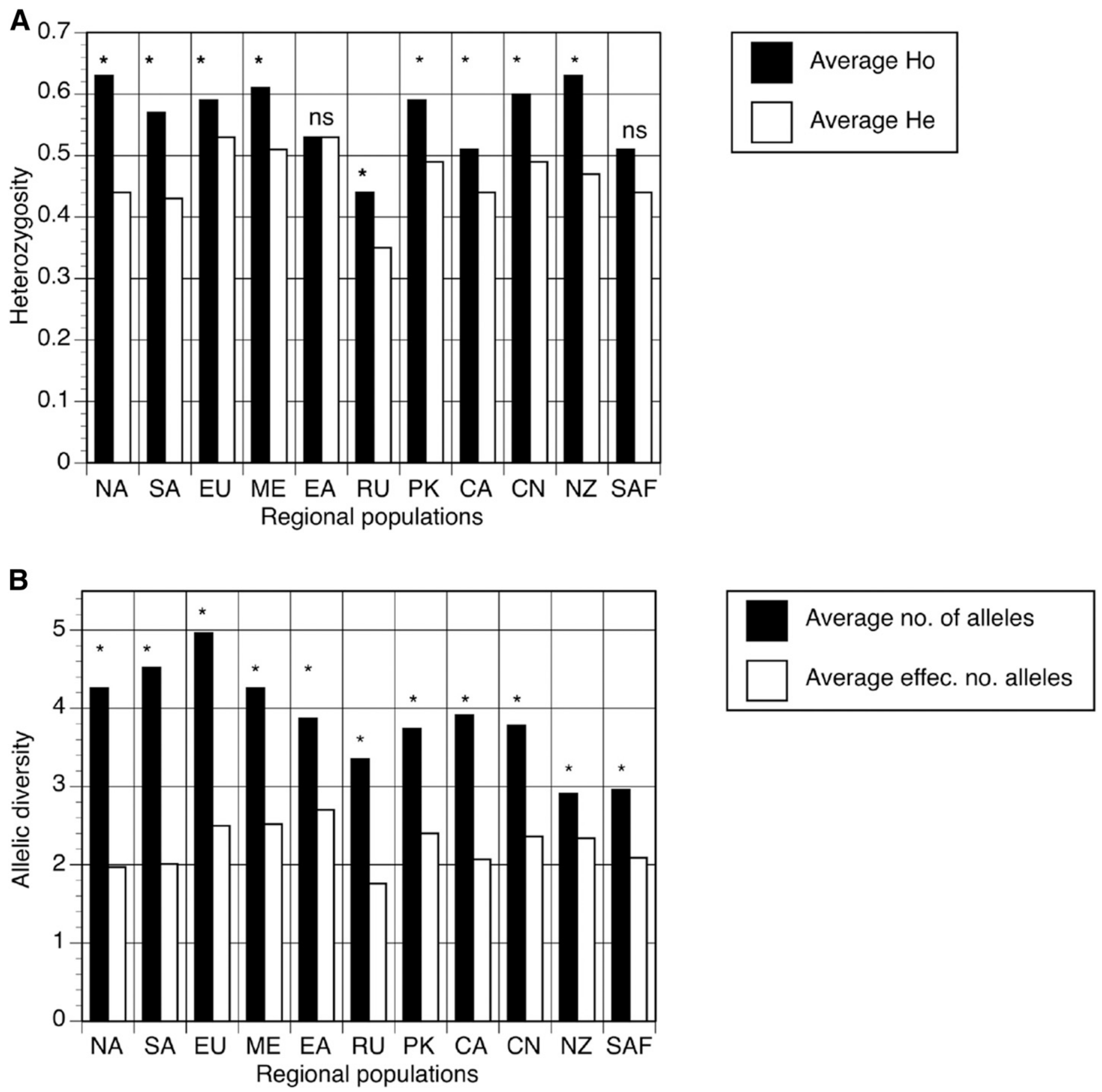

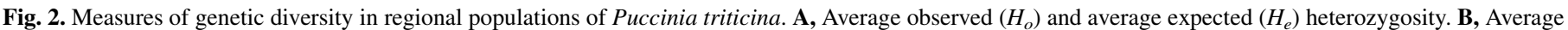

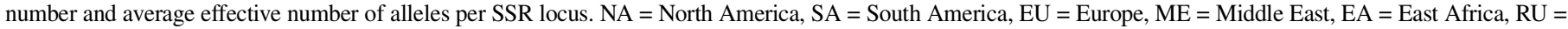
Russia, $\mathrm{PK}=$ Pakistan, $\mathrm{CA}=$ Central Asia, $\mathrm{CN}=$ China, $\mathrm{NZ}=$ New Zealand, $\mathrm{SAF}=$ South Africa, and ns $=$ nonsignificant value of inbreeding coefficient $F_{I S}$. 


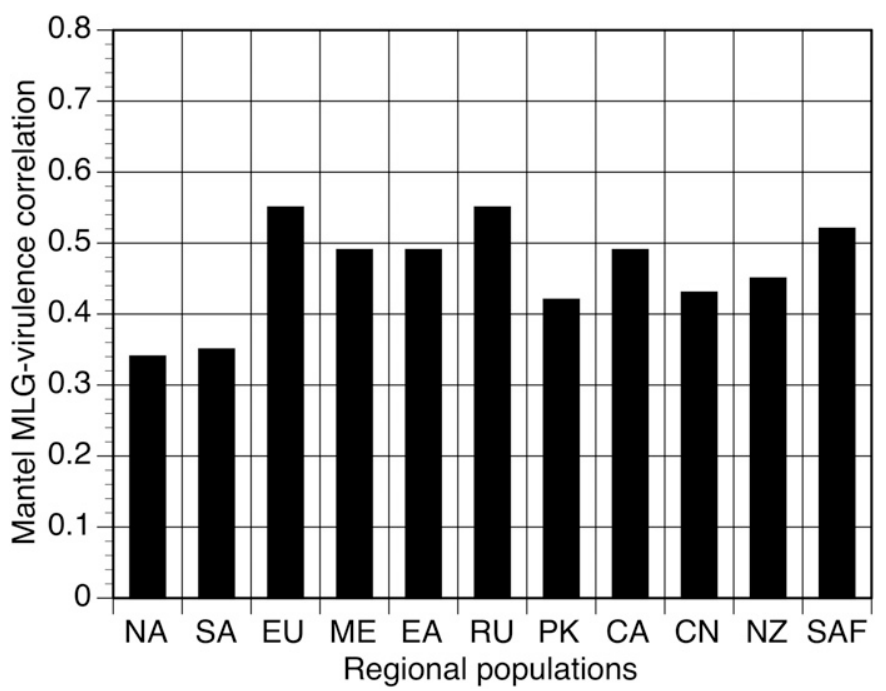

Fig. 3. Mantel correlation coefficient between multilocus genotypes (MLGs) and virulence phenotypes of Puccinia triticina isolates in regional populations. All correlation coefficients were significant at $P<0.01$. NA $=$ North America, $\mathrm{SA}=$ South America, $\mathrm{EU}=$ Europe, $\mathrm{ME}=$ Middle East, $\mathrm{EA}=$ East Africa, $\mathrm{RU}=$ Russia, $\mathrm{PK}=$ Pakistan, $\mathrm{CA}=$ Central Asia, $\mathrm{CN}=$ China, $\mathrm{NZ}=\mathrm{New}$ Zealand, and SAF $=$ South Africa.
Europe, the Middle East, and East Africa were indicated with the suffix durum. Isolates from Ethiopia virulent to durum wheat and avirulent to Thatcher were in the EA durum E group. In the AMOVA, the overall $F_{S T}$ was 0.30 , with $78 \%$ of the variation within individuals (heterozygosity), $22 \%$ among the 40 groups, and $0 \%$ among individuals within groups, which indicated that the groups were useful for determining the genetic relationships of isolate groups from different regions.

Most of the MLG groups had isolates that were collected over a span of years, with only a few groups with isolates that were collected in a specific year. Historical reference isolates in NA1, NA4, and NA5 from the 1950s had similar or identical MLGs to isolates from the mid-2000s (Table 2). The groups SA1, SA2, EU1, and EU5 had isolates collected in the early 1980s up to the mid- to late 2000s. Isolates in EA1, EA2, and the EA durum E group had isolates that were collected in the 1980s up to 2012. Most of the other groups had isolates that were collected in the mid-1990s to the mid- to late 2000s or from the mid-2000s to 2013. There were some MLGs found in a specific year, as MLGs in EU2, EU6, and PK3 were found only in 2009, 1995, and 2013, respectively. Twentyseven of the 29 isolates in EU2 were collected in Turkey in 2009, and all six isolates in EU6 were from Germany, Hungary, and Czechoslovakia in 1995. All isolates in PK3 were from Pakistan and Bhutan in 2013. Isolates were obtained from New Zealand in only 1997. Overall, however, there appeared to be relatively few MLG groups that were found in only 1 year.

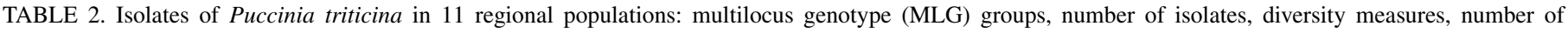
virulence phenotypes, and years collected

\begin{tabular}{|c|c|c|c|c|c|c|c|}
\hline Continental population & MLG group & Isolates $(n)$ & MLGs $(n)$ & $\begin{array}{l}\text { Simpson unbiased }(\lambda) \\
\text { diversity }\end{array}$ & Effective MLGs $(n)$ & $\begin{array}{c}\text { Virulence } \\
\text { phenotypes }(n)\end{array}$ & Year(s) \\
\hline \multirow[t]{6}{*}{ North America } & NA1 & 12 & 11 & 0.903 & 10.3 & 9 & 1954 to 2005 \\
\hline & NA2 & 24 & 13 & 0.795 & 4.8 & 19 & 1984 to 2004 \\
\hline & NA3 & 21 & 11 & 0.780 & 4.5 & 10 & 1996 to 2005 \\
\hline & NA4 & 6 & 3 & 0.500 & 2.0 & 4 & 1959 to 2005 \\
\hline & NA5 & 62 & 16 & 0.720 & 3.6 & 46 & 1959 to 2005 \\
\hline & NA durum & 7 & 4 & 0.694 & 3.3 & 1 & 2002 to 2009 \\
\hline \multirow{5}{*}{ South America } & SA1 & 9 & 7 & 0.840 & 6.2 & 6 & 1982 to 2004 \\
\hline & SA2 & 50 & 25 & 0.928 & 13.9 & 41 & 1981 to 2006 \\
\hline & SA3 & 45 & 26 & 0.925 & 13.4 & 25 & 2004 to 2008 \\
\hline & SA4 & 7 & 7 & 0.857 & 7.0 & 7 & 1987 to 2008 \\
\hline & SA durum & 11 & 10 & 0.893 & 9.3 & 6 & 1988 to 2008 \\
\hline \multirow[t]{8}{*}{ Europe } & EU1 & 19 & 14 & 0.903 & 10.3 & 14 & 1981 to 2006 \\
\hline & EU2 & 29 & 14 & 0.828 & 5.8 & 24 & 2009 \\
\hline & EU4 & 15 & 5 & 0.444 & 1.8 & 12 & 1995 to 2009 \\
\hline & EU5 & 16 & 12 & 0.898 & 9.8 & 15 & 1982 to 2009 \\
\hline & EU6 & 6 & 3 & 0.500 & 2.0 & 6 & 1995 \\
\hline & EU7 & 14 & 7 & 0.704 & 3.4 & 11 & 1993 to 2009 \\
\hline & EU8 & 23 & 14 & 0.896 & 9.6 & 14 & 1995 to 2009 \\
\hline & EU durum & 15 & 12 & 0.880 & 8.3 & 10 & 1994 to 2015 \\
\hline \multirow[t]{3}{*}{ Middle East } & ME1 & 31 & 14 & 0.743 & 3.8 & 30 & 1998 to 2006 \\
\hline & ME2 & 39 & 20 & 0.810 & 5.3 & 35 & 1992 to 2006 \\
\hline & ME durum & 15 & 13 & 0.916 & 11.8 & 12 & 1990 to 2015 \\
\hline \multirow{4}{*}{ East Africa } & EA1 & 12 & 4 & 0.417 & 1.7 & 8 & 1984 to 2012 \\
\hline & EA2 & 12 & 6 & 0.694 & 3.3 & 12 & 1988 to 2012 \\
\hline & EA durum & 7 & 2 & 0.245 & 1.3 & 1 & 2002 to 2012 \\
\hline & EA durum $\mathrm{E}$ & 9 & 9 & 1.00 & 9.0 & 1 & 1987 to 2012 \\
\hline \multirow[t]{2}{*}{ Russia } & RU1 & 40 & 16 & 0.906 & 10.6 & 23 & 2006 to 2010 \\
\hline & RU2 & 26 & 20 & 0.923 & 13.0 & 18 & 2006 to 2010 \\
\hline \multirow[t]{3}{*}{ Pakistan } & PK1 & 17 & 9 & 0.789 & 4.7 & 11 & 2010 to 2013 \\
\hline & PK2 & 12 & 10 & 0.833 & 6.0 & 10 & 2011 to 2014 \\
\hline & PK3 & 9 & 9 & 0.889 & 9.0 & 3 & 2013 \\
\hline \multirow[t]{4}{*}{ Central Asia } & CA1 & 18 & 14 & 0.901 & 10.1 & 13 & 2002 to 2005 \\
\hline & CA2 & 46 & 39 & 0.971 & 34.1 & 33 & 2002 to 2005 \\
\hline & CA3 & 15 & 10 & 0.726 & 6.1 & 13 & 2002 to 2005 \\
\hline & CA4 & 20 & 9 & 0.620 & 2.6 & 17 & 2002 to 2004 \\
\hline \multirow[t]{3}{*}{ China } & CN1 & 36 & 23 & 0.924 & 13.2 & 25 & 2009 to 2010 \\
\hline & $\mathrm{CN} 2$ & 32 & 9 & 0.682 & 3.1 & 19 & 2009 to 2010 \\
\hline & $\mathrm{CN} 3$ & 13 & 4 & 0.568 & 2.3 & 4 & 2009 to 2010 \\
\hline New Zealand & $\mathrm{NZ}$ & 10 & 9 & 0.880 & 8.3 & 8 & 1997 \\
\hline South Africa & SAF & 21 & 11 & 0.807 & 5.2 & 18 & 1996 to 2010 \\
\hline
\end{tabular}


The effect of clonality can be seen in the genotypic diversity measures of the MLG groups (Table 2). For example, isolates in the NA5 group had 16 MLGs and 46 virulence phenotypes among the 62 isolates and a Simpson diversity $(\lambda)$ of 0.72 . Many of these isolates had the same MLG but had different virulence phenotypes. The effective number of MLG was 3.6, which indicated the presence of many clones in this group, since this value is the number of evenly distributed MLGs needed to obtain the observed Simpson diversity. Other MLG groups with over 25 isolates (SA2, SA3, EU2, ME1, ME2, RU1, RU2, CN1, and CN2) also had large differences in the effective number of MLGs compared with the observed numbers. Most of these groups had an effective number of MLGs that were less than half the observed number. However, not all of the larger MLG groups had diversity indicators of clonality, since group CA2 was highly diverse with a Simpson index of 0.971 and an effective number of MLGs of 34.1, which was close to the observed 39 MLGs. This group was also highly diverse for virulence phenotypes with 33 among the 46 isolates. Groups SA4, EA durum E, and PK3 that had fewer than 10 isolates were also highly diverse with equal numbers of isolates and total numbers of observed MLGs.

The genetic distance between the MLG groups is visualized in Figure 4. Isolates that are virulent to durum wheat in groups ME durum, NA durum, SA durum, EU durum, and EA durum were highly related and were the most genetically distant groups. Isolates in EA durum $\mathrm{E}$ were also genetically distinct and were not closely related to any other MLG group. Isolates from common wheat in CN3 and EU1 were also not closely related to any other MLG groups. With the exception of EU5, the remaining MLG groups grouped in three branches. Each branch had MLG groups that were from different regions. Although isolates in NA2 and CN2 were in branches with other MLG groups, they were not closely related to other groups. Most pairwise combinations of MLG groups had significant levels of $F_{S T}$ with $P<0.001$ (data not shown); however, 44 pairs of MLG groups from different regions were more closely related and had $F_{S T}$ values with significance levels of $P \geq 0.01$ (Supplementary Table S3). Most of the MLG group pairs with lower values of $F_{S T}$ were also closely related for Nei's genetic distance (Fig. 4).

Occurrence of MLGs across regions. Among the 424 MLGs, 27 were found in more than one region (Table 3; Supplementary
Table S4). The $P_{\text {sex }}$ values for each genotype, which is the probability of sampling two or more identical MLGs in sexual populations (Stenberg et al. 2003), were exceedingly low $(P<$ 0.001 ), which indicated that isolates with identical MLGs in different continents were clones. Isolates with identical MLGs were also more related for virulence phenotype, as these had a significantly smaller average virulence difference ( 0.00 to 4.95$)$ compared with the average difference of 7.56 ( 0.004 standard error) in the total population. MLG 46 had the highest number of isolates at 47 , as well as the highest number of virulence phenotypes at 35 (Table 3). Isolates with this MLG were very common in the United States, Canada, and Egypt and with a single isolate in Chile (Fig. 5). MLG 99 was the second most common, with 22 isolates and 19 virulence phenotypes (Table 3), which were found in Ethiopia, Kenya, Turkey, Egypt, and Israel (Fig. 5). Isolates in MLG 33 were found in Uruguay, the United States, the United Kingdom, Turkey, and Ethiopia, and isolates in MLG 36 were found in the United States, Chile, Ethiopia, Pakistan, Turkey, Kenya, and France (Fig. 5). These two MLGs are closely related and were dominated by virulence phenotypes that are virulent to $\mathrm{Lrl7}$ and $\mathrm{Lr} 3 \mathrm{bg}$ and avirulent to $L r 2 a$ and $L r 28$. Isolates in MLG 35 are highly related to MLG 33 and MLG 36, are also highly similar for virulence, and were found in Uruguay, Argentina, and the United States (Table 3). Isolates in MLG 6 were found in Uruguay, Egypt, France, the United Kingdom, the Czech Republic, Turkey, and Uzbekistan (Fig. 5). Isolates in MLG 25 were widespread and were found in Egypt, Ukraine, Russia, Turkey, Kazakhstan, Uzbekistan, and China. Isolates in MLG 72 and MLG 75 were highly related, with virulence to durum wheat cultivars (Table 3), and were found in Ethiopia, France, and Israel and in the United States, Mexico, and Ethiopia, respectively. Isolates in the other MLGs shown in Table 3 were lower in number but were still found in two to four regions.

Thirteen of the MLGs listed in Table 3 also had isolates with identical virulence phenotypes (Table 4). Isolates in MLG 36 with virulence phenotype MCDSS were the most widespread and were found in Kenya, Ethiopia, Chile, Turkey, France, and the United States from 2003 to 2011. Isolates in MLG 33 that also had virulence phenotype MCDSS were found in Uruguay, Turkey, and the United States from 2000 to 2009. Isolates with rare virulence

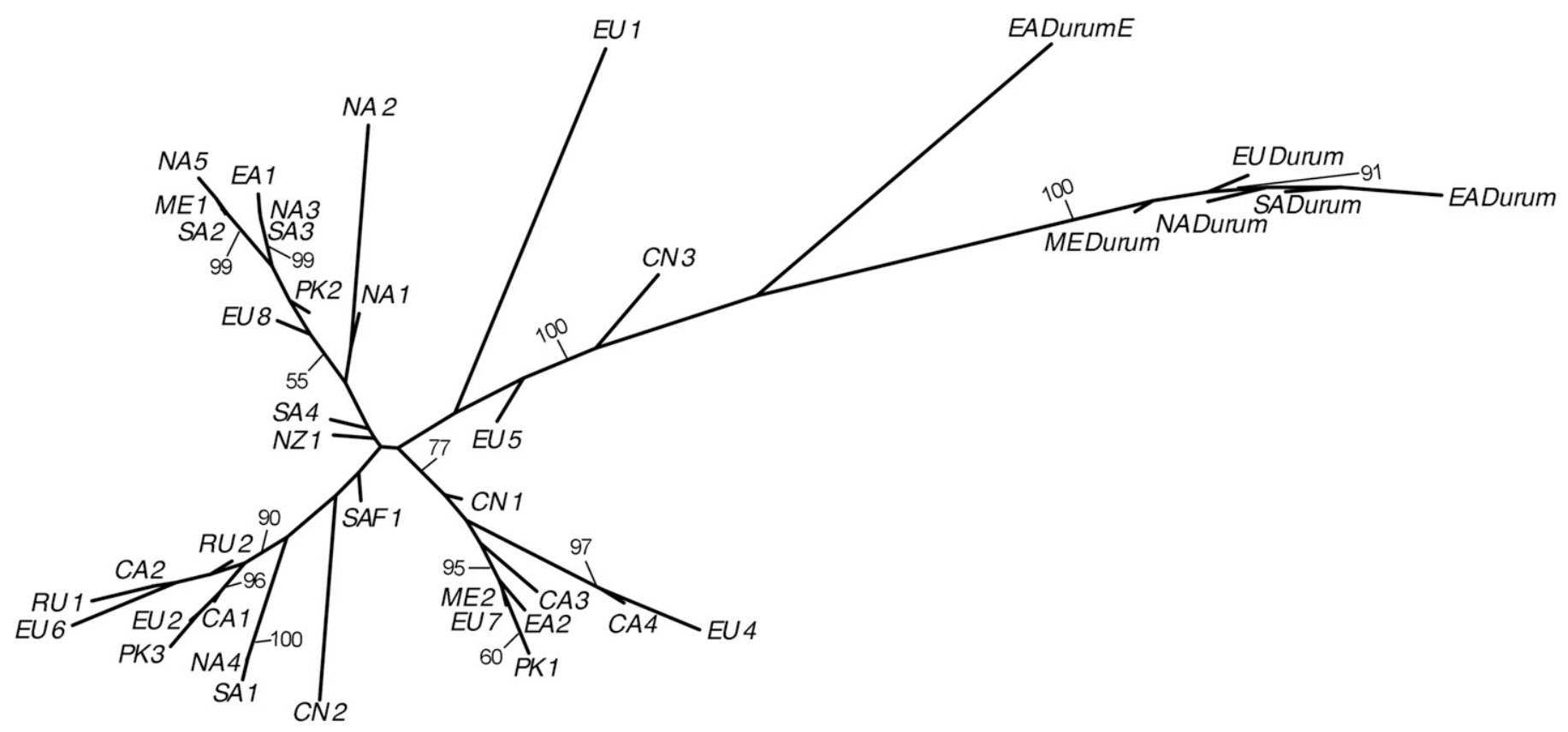

Fig. 4. Neighbor-joining plot of Nei's genetic distance of multilocus genotypes between Puccinia triticina isolates in 40 multilocus genotype groups within regional populations. The plot is based on 1,000 bootstrap samples with support values $>50 \%$ indicated at nodes. NA $=$ North America, $\mathrm{SA}=\mathrm{South}$ America, EA $=$ East Africa, $\mathrm{ME}=$ Middle East, $\mathrm{NZ}=$ New Zealand, $\mathrm{SAF}=$ South Africa, EU = Europe, $\mathrm{PK}=$ Pakistan, $\mathrm{CN}=\mathrm{China}, \mathrm{CA}=\mathrm{Central}$ Asia, and RU = Russia. 
phenotypes and identical MLGs were also found in widely separated regions. Isolates in MLG 39 with the rare virulence phenotype LCGHK (virulent to $L r 1, L r 26$, and $L r 11$ and avirulent to $L r 2 a, L r 2 c$, and $L r 3$ ) were found in Brazil, Israel, and New Zealand.
Isolates with virulence phenotype SBDGK (avirulent to $L r 3$ and virulent to $\operatorname{Lr} 17, \mathrm{Lr} 10, \mathrm{Lr} 14 b, \mathrm{Lr} 20$, and $L r 28$ ) in MLG 79 were found in Uruguay and Canada in 2004 and 1959, respectively. Isolates in MLG 58 were unique since the five isolates had virulence

TABLE 3. Multilocus genotype (MLG) groups of Puccinia triticina sampled across more than one regional population and average virulence difference of isolates within and between MLG groups

\begin{tabular}{|c|c|c|c|c|c|}
\hline MLG no. & Isolates $(n)$ & MLG groups (isolates, $n)^{\mathrm{a}}$ & $P_{\text {sex }}$ & $\begin{array}{c}\text { Virulence } \\
\text { phenotypes }(n)\end{array}$ & $\begin{array}{c}\text { Average virulence } \\
\text { difference (standard error) }\end{array}$ \\
\hline 6 & 15 & SA4 (1), ME2 (2), EU4 (11), CA4 (1) ${ }^{\mathrm{b}}$ & 0.00 & 13 & $2.64(0.13)$ \\
\hline 7 & 3 & ME2 (1), EU7 (1), CN1 (1) & $9.23 \mathrm{E}-14$ & 3 & $2.66(1.52)$ \\
\hline 25 & 18 & ME2 (1), EU2 (7), ${ }^{\mathrm{b}} \mathrm{CN} 1$ (1), RU2 (5), ${ }^{\mathrm{b}} \mathrm{CA} 1$ (4) & $1.16 \mathrm{E}-11$ & 14 & $2.75(0.13)$ \\
\hline 33 & 19 & EA1 (1), SA3 (7), ${ }^{\mathrm{b}}$ EU8 (2), ${ }^{\mathrm{b}}$ NA3 (9) ${ }^{\mathrm{b}}$ & 7.94E-09 & 13 & $4.11(0.18)$ \\
\hline 35 & 5 & SA3 (4), NA3 (1) & $6.75 \mathrm{E}-09$ & 5 & $3.4(0.32)$ \\
\hline 36 & 17 & EA1 (9), ${ }^{\mathrm{b}} \mathrm{SA} 3$ (3), ${ }^{\mathrm{b}} \mathrm{EU} 8(3),{ }^{\mathrm{b}}$ PK2 (1), NA3 (1) & $3.15 \mathrm{E}-09$ & 7 & $1.54(0.12)$ \\
\hline 42 & 9 & SA2 (1), ME1 (1), NA5 (7) & $4.08 \mathrm{E}-11$ & 8 & $3.61(0.34)$ \\
\hline 46 & 47 & SA2 (1), ME1 (15), NA5 (31) & 3.11E-09 & 35 & $4.89(1.44)$ \\
\hline 47 & 3 & ME1 (2), ${ }^{\mathrm{b}}$ NA5 (1) ${ }^{\mathrm{b}}$ & $3.24 \mathrm{E}-10$ & 2 & $0.67(0.58)$ \\
\hline 49 & 5 & SA2 (1), ME1 (2), NZ (1), NA5 (1) & $6.48 \mathrm{E}-10$ & 5 & $4.6(0.65)$ \\
\hline 52 & 4 & EA1 (1), ${ }^{\mathrm{b}}$ EU8 (1), ${ }^{\mathrm{b}}$ NA5 (2) & $1.08 \mathrm{E}-11$ & 3 & $2.5(0.98)$ \\
\hline 58 & 5 & SA2 (2), ${ }^{\mathrm{b}}$ NZ (1), ${ }^{\mathrm{b}}$ NA1 (2) & 7.32E-10 & 1 & 0.0 \\
\hline 59 & 3 & ME2 (1), EU5 (2) & 0.00 & 3 & $1.3(0.33)$ \\
\hline 79 & 5 & SA $(1),{ }^{b}$ NA4 $(4)^{b}$ & $1.25 \mathrm{E}-09$ & 3 & $0.60(0.16)$ \\
\hline 82 & 2 & SA1 (1), NA4 (1) & $5.08 \mathrm{E}-09$ & 2 & $1.0(0.0)$ \\
\hline 83 & 3 & EU2 (2), PK3 (1) & $7.75 \mathrm{E}-12$ & 3 & $1.33(0.34)$ \\
\hline 84 & 11 & EU2 (9), RU2 (1), CA1 (1) & $1.52 \mathrm{E}-11$ & 10 & $2.65(1.27)$ \\
\hline 92 & 2 & ME2 (1), EU7 (1) & $9.23 \mathrm{E}-14$ & 2 & $3.0(0.0)$ \\
\hline 99 & 22 & EA2 (6), ${ }^{\mathrm{b}}$ ME2 (16) & $1.61 \mathrm{E}-11$ & 19 & $4.22(0.15)$ \\
\hline Total isolates & 831 & & & 497 & $7.56(0.004)$ \\
\hline
\end{tabular}

a SA = South America, ME = Middle East, EU = Europe, $\mathrm{CA}=$ Central Asia, $\mathrm{CN}=$ China, $\mathrm{PK}=$ Pakistan, RU $=$ Russia, EA = East Africa, NA = North America, $\mathrm{NZ}=$ New Zealand, and ETH $=$ Ethiopia.

b MLGs with identical virulence phenotype across continental regions.

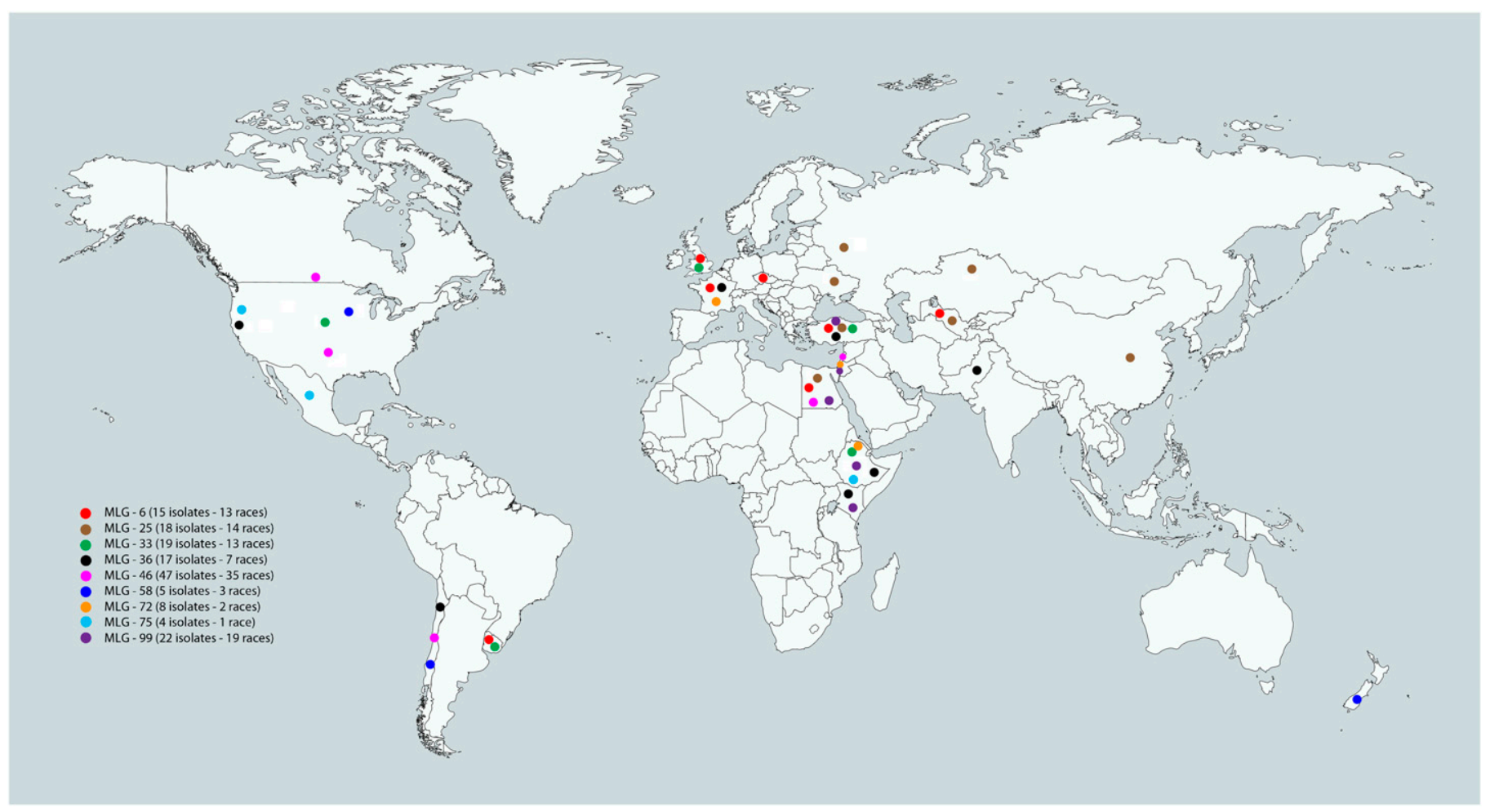

Fig. 5. Distribution of nine multilocus genotypes (MLGs) of Puccinia triticina across different continental regions. 
phenotype BBBDJ, with virulence only to genes $\mathrm{Lr} 14 a$, Lrl 4 b and Lr20. These relatively avirulent isolates were widely dispersed in time and geographically and were found in Chile, the United States, and New Zealand from 1954 to 2006 (Table 4). Isolates with virulence phenotype BBBQJ that are highly virulent to durum wheat in MLG 72 were found in Israel, France, and Ethiopia and isolates in MLG 75 with the same virulence were found in Mexico, the United States, and Ethiopia. Isolates in MLGs 6, 25, 47, 52, 65, and 99 also had isolates with identical virulence phenotypes that were found in at least two regions (Table 4).

\section{DISCUSSION}

This study showed that at a global level, populations of $P$. triticina are highly diverse for molecular genotype and also for virulence to leaf rust resistance genes. The widespread occurrence of MLGs across different regions and decades in time indicated that $P$. triticina has the potential for long-distance migration, which has likely occurred in the past and in more recent years. Host selection, asexual reproduction, and movement of genotypes-virulence phenotypes have influenced genetic variation in the regional $P$. triticina populations across different regions.

The regional populations all had estimates of genetic diversity that were characteristic of clonal populations. This is also observed with the consistent level of association between virulence phenotypes and MLGs across the regional populations and the small number of virulence differences between isolates with identical MLGs. Selection for virulence phenotypes occurs within clonal MLG groups, which maintains the correlation between molecular genotypes and virulence. Despite the lack of susceptible aecial hosts in most regions and dependence on clonal reproduction, $P$. triticina is a very successful pathogen of wheat, occurring regularly in many wheat production regions of the world, with many virulence phenotypes. It has the largest genome of the three wheat rust pathogens at $135 \mathrm{Mb}$ (Cuomo et al. 2017), and mobile elements and repetitive DNA accounted for $51 \%$ of contig bases. The high proportion of mobile and repetitive elements in the genome may be a source of diversity for genes that are involved with virulence to host resistance genes (Ali et al. 2014b), resulting in the regular appearance of new races. In contrast, populations of $P$. graminis $\mathrm{f}$. sp. tritici (wheat stem rust pathogen) have much less virulence diversity in areas such as North America, where the aecial host Berberis vulgaris is largely absent (Roelfs and Groth 1980).

Some MLG groups were found only in specific years. This could be attributable to sampling of isolates, as greater numbers in other years may have detected these MLGs, or the occurrence of MLGs in only one single year could be a result of their subsequent decline in later years. For example, in North America, isolates with a SBDGK virulence phenotype in the NA4 group, which is avirulent to Lr3, were predominant from the 1920s to the mid-1940s (Kolmer 1991). However, this virulence phenotype declined rapidly after the release of winter wheat cultivars in the mid-1940s with the Lr3 resistance gene (Browder 1980; Samborski 1985). In current annual virulence surveys (Kolmer and Hughes 2017), isolates with the SBDGK phenotype are detected rarely and at low frequencies. Differentiation based on time of collection was also detected in populations of P. striiformis f. sp. tritici (wheat stripe rust) in China, Nepal, the Middle East, East Africa, and the Mediterranean region (Thach

TABLE 4. Multilocus genotypes (MLGs) of Puccinia triticina with identical virulence phenotypes found across different regional populations

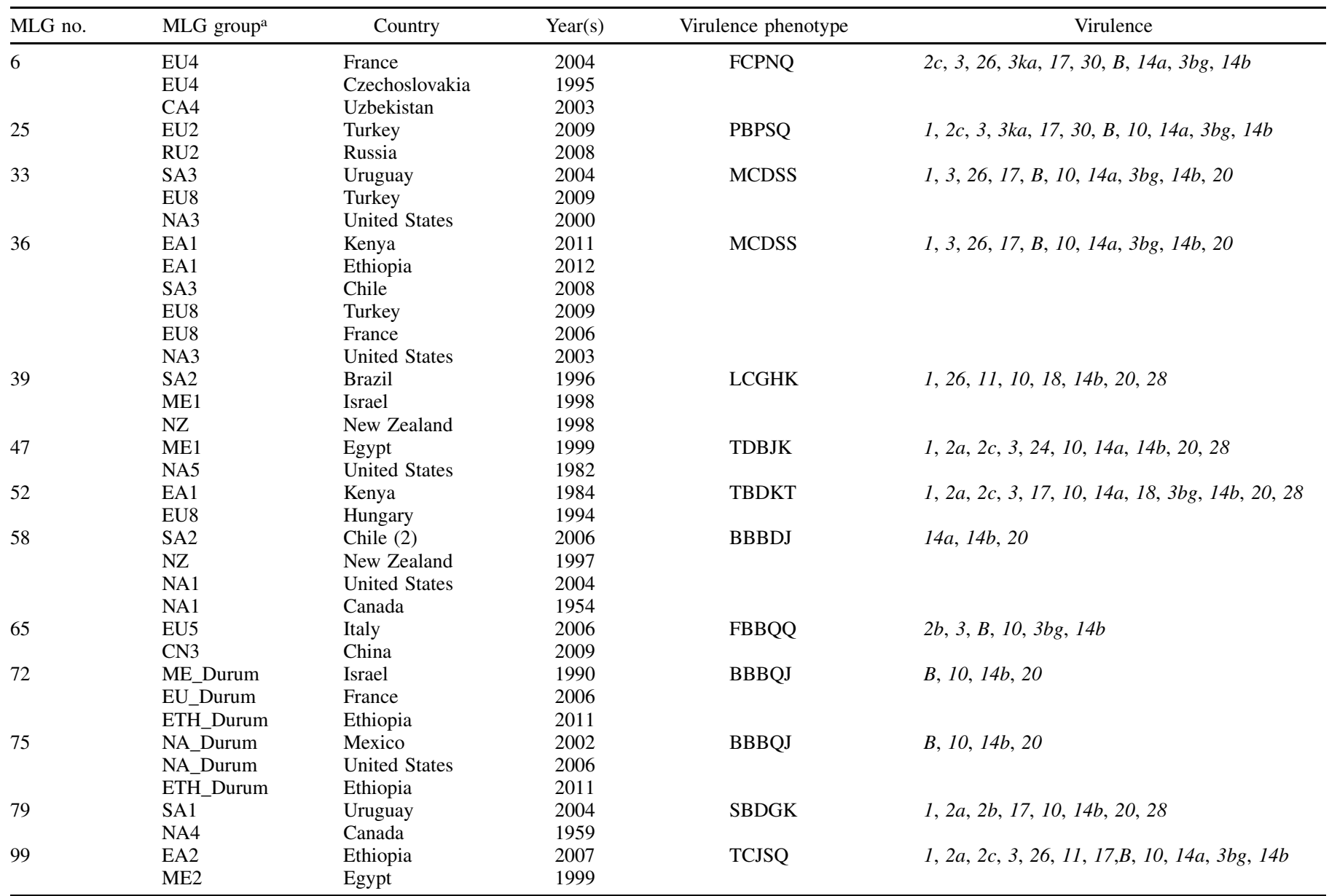

${ }^{a}$ EU $=$ Europe, $\mathrm{CA}=$ Central Asia, RU $=$ Russia, $\mathrm{SA}=$ South America, NA = North America, EA = East Africa, ME = Middle East, NZ = New Zealand, and $\mathrm{CN}=$ China . 
et al. 2016). This was attributed to migration of new $P$. striiformis genotypes and displacement of older genotypes.

Sampling is a critical aspect in all population studies. Populations with small sample sizes that were collected in only one or a few years may not be representative of the overall populations. This can lead to questionable estimates of genetic diversity and also give misleading estimates of genetic relatedness between populations. A limitation of this study was the variation in size of the sampled collections across different years in the regional populations. Ideally all of the populations would have sampled in equal numbers within a uniform time period. The population from New Zealand had the smallest sample size and was collected in only 1 year. Additional collections over a period of years would have been a better representation of this population. Despite this issue, we were still able to detect isolates from New Zealand that had identical MLGs to other isolates across different regions over a period of years, indicating migration of $P$. triticina MLGs and virulence phenotypes. We were also able to detect isolates with identical MLGs that had other rare virulence phenotypes in more than one regional population across decades in time.

There was evidence of migration between adjacent regions, as the regions in closer proximity (North America-South America, Russia-Central Asia, and Middle East-East Africa) had a smaller genetic distance compared with more distant regions and also had MLGs in common. North America and South America may have received common introductions of $P$. triticina during European colonization and establishment of agricultural settlements. The similarity of the Russian and Central Asia and the East Africa and Middle East populations is likely attributable to the gradual stepwise expansion of MLGs/phenotypes by windblown urediniospores across these regions. Migration of wheat rust pathogens across large land areas is well documented. Phenotypes of P. graminis f. sp. tritici with virulence to $\mathrm{Sr} 31$ and $\operatorname{Sr} 38$ have gradually spread across East Africa (Jin et al. 2008, 2009; Wanyera et al. 2006) into parts of the Middle East and Southwest Asia. Similarly, phenotypes of $P$. striiformis $\mathrm{f}$. sp. tritic $i$ with virulence to Yr9 spread from East Africa to the Middle East and Asia (Ali et al. 2014a; Hovmøller et al. 2011). Phenotypes of P. triticina that are found in the winter wheat region of the southern Great Plains of the United States (Kolmer et al. 2006) are also detected later in the same year on spring wheat in the prairies of western Canada (McCallum and Seto-Goh 2006).

MLG groups from almost all regions were highly related to MLG groups from other regions, reducing the association between geographic origin and MLG. Long-distance migration of $P$. triticina between distant continents must be occurring. This can also be hypothesized because isolates with the same MLG and virulence phenotype were found in different continents. Migration events must have occurred in the past, as exemplified by MLG 58 found in New Zealand, Canada, the United States, and Chile from 1954 to 2007. More recent migration events have also occurred. MCDSS, MBDSS, and other phenotypes with virulence to $\mathrm{Lrl} 7$ and $\mathrm{Lr} 3 \mathrm{bg}$ and avirulence to $L r 2 a$ and $L r 28$ were first found in large numbers in the mid-1990s in the United States (Long et al. 2000) and Canada (Kolmer 1998), in South America in 1999 (Germán et al. 2007), and in France in 2000 and 2001 (Goyeau et al. 2006). These isolates are all highly related for MLGs and are in groups NA3, SA3, and EU8, respectively. Isolates with MCDSS phenotype in MLG 33 and MLG 36 were found in North America, South America, Europe, Southwest Asia, and East Africa. In addition, isolates in PK2 with MCDSS and MBDSS phenotypes were highly related for MLGs to isolates with the identical and similar phenotypes in EU8, NA3, SA3, and EA1. Similarly, the spread of highly related phenotypes and genotypes of $P$. triticina with virulence to durum wheat cultivars in many durum wheat regions also indicates migration between distant continents.

Examples of long-distance migration of wheat rust fungi are replete. The most well-known migration event is the introduction of
P. striiformis f. sp. tritici to Australia from northwest Europe in 1979 (Wellings and McIntosh 1990). Genotypes of P. striiformis with adaptation to higher temperatures have migrated to Australia, North America, and Europe since the early 2000s (Ali et al. 2014a; Hovmøller et al. 2008; Markell and Milus 2008). Stripe rust was also introduced to South Africa in 1996 (Pretorius et al. 1997), likely from the Mediterranean region. Virulence data and SSR genotyping support the hypothesis that wheat stem rust migrated from South Africa to Australia in the late 1960s (Visser et al. 2019).

Overall the $P$. triticina collections from hexaploid wheat in all regions were more diverse for molecular and virulence variation, compared with isolates from tetraploid durum wheat. While collections of isolates from durum wheat in geographically distant regions were closely related for molecular genotypes, MLG groups of isolates from common wheat from the same region were often highly genetically divergent. Isolates of $P$. triticina from durum wheat have closely related molecular genotypes and are not diverse for virulence phenotype, as found in France (Goyeau et al. 2006, 2011), Israel (Kosman et al. 2013), and Mexico (Singh et al. 2004). The reduced level of genetic and virulence diversity may be attributable to a smaller genetic basis of leaf rust resistance in the durum wheat cultivars. Most durum cultivars are susceptible to P. triticina phenotypes with virulence to $L r 72$ (Herrera-Foessel et al. 2014) that have spread to South America (Ordoñez and Kolmer 2007a), Mexico (Singh et al. 2004), the Middle East (Ordoñez and Kolmer 2007b), and Europe (Goyeau et al. 2011) since the early 2000s. The preponderance of durum cultivars that are susceptible to these phenotypes (Singh et al. 2004) suggests that durum wheat germplasm as a whole is not very diverse for effective leaf rust resistance genes. In contrast, many leaf rust resistance genes have been documented in common wheat (McIntosh et al. 1995, 2017). Selection for virulence to these numerous leaf rust resistance genes has diversified $P$. triticina populations. For example, in the United States numerous common wheat cultivars in different market classes are grown that differ for leaf rust resistance genes. As a result, regional populations of $P$. triticina differ for predominant virulence phenotypes, and 50 to 70 virulence phenotypes are found annually (Kolmer and Hughes 2017). The diversity of deployed resistance genes in the cultivars has placed a continual selection pressure on $P$. triticina in North America, resulting in a population that is highly diverse for virulence phenotypes. In North America, six MLG groups were described (Ordoñez and Kolmer 2009), each with virulence phenotypes that have been selected by host resistance genes.

Isolates in the EA durum E MLG group were found only in Ethiopia. These isolates are highly virulent to durum wheat cultivars but unlike isolates in the other durum MLG groups, they are avirulent to many susceptible common wheat cultivars such as Thatcher. Ethiopia is a unique host environment because land races of emmer and durum wheat are still grown (Eticha et al. 2006) together with hexaploid wheat cultivars (International Maize and Wheat Improvement Center 2015). The durum adapted isolates that are avirulent to the susceptible common wheat cultivars have been collected from tetraploid landraces and modern durum wheat cultivars (Kolmer and Acevedo 2016). These isolates have been hypothesized to be the oldest form of $P$. triticina on tetraploid or common wheat (Liu et al. 2014).

The center of origin of $P$. triticina is likely the Fertile Crescent region of Mesopotamia, where alternate hosts (Tatlidil et al. 2005) and wheat progenitors are found (Feldman 2001). Coalescence analysis (Liu et al. 2014) of DNA sequence indicated that $P$. triticina types adapted to either tetraploid durum wheat or hexaploid common wheat diverged from a common ancestor found only on the diploid wheat progenitor Aegilops speltoides (Yehuda et al. 2004) in a process that paralleled the evolution of polyploid wheat in the Fertile Crescent (Salamini et al. 2002). As such, P. triticina is a longestablished pathogen of wheat found in many wheat growing regions, as indicated by the occurrence of isolates with similar or 
identical MLGs in distant continents. Leaf rust on wheat was first noted to be present in Australia in 1825 (McAlpine 1895) shortly after European settlement and in South Africa in 1911 (Pole Evans 1911). In contrast, $P$. striiformis, which was hypothesized to originate in the Himalayan region (Ali et al. 2014a), only arrived in Australia in 1979 and in South Africa in 1996. Regional populations of $P$. striiformis were also strongly associated with MLG groups (Ali et al. 2014a), compared with $P$. triticina that had highly related MLG groups from different continents. Although P. striiformis and $P$. triticina are both wind-dispersed rust pathogens of wheat with many different virulence phenotypes, they are very different with regard to distribution of genetic variation across regions and evolutionary history.

In conclusion, our study found that $P$. triticina is a highly diverse pathogen of wheat, with many highly related MLG groups widely distributed across wheat growing regions worldwide. The relative broad environmental adaptation (Roelfs 1989; Roelfs et al. 1992) and the ability of $P$. triticina to adapt to the continuously changing landscape of resistance genes in wheat cultivars, combined with the capability to produce millions of infective clonal urediniospores that can be wind dispersed over thousands of kilometers, has contributed to the persistence and widespread occurrence of this pathogen.

\section{ACKNOWLEDGMENTS}

We thank all of the collaborators who have sent collections of $P$. triticina to the USDA-ARS Cereal Disease Laboratory for virulence typing and genotype analysis. We thank Kun Xiao for excellent greenhouse and laboratory assistance. Mention of trade names or commercial products in this publication is solely for the purpose of providing specific information and does not imply recommendation or endorsement by the U.S. Department of Agriculture.

\section{LITERATURE CITED}

Ali, S., Gladieux, P., Leconte, M., Gautier, A., Justesen, A. F., Hovmøller, M. S., Enjalbert, J., and deVallavieille-Pope, C. 2014a. Origin, migration routes and worldwide population genetic structure of the wheat yellow rust pathogen Puccinia striiformis f. sp. tritici. PLoS Pathog. 10: e1003903.

Ali, S., Laurie, J. D., Linning, R., Cervantes-Chavez, J. A., Gaudet, D., and Bakkeren, G. 2014b. Immunity-triggering effector from the barley smut fungus Ustilago hordei resides in an Ustilaginaceae-specific cluster bearing signs of transposable element-assisted evolution. PLoS Pathog 10:e1004223.

Bebber, D. P., Holmes, T., and Gurr, S. J. 2014. The global spread of crop pests and pathogens. Glob. Ecol. Biogeogr. 23:1398-1407.

Bolton, M. D., Kolmer, J. A., and Garvin, D. F. 2008. Wheat leaf rust caused by Puccinia triticina. Mol. Plant Pathol. 9:563-575.

Browder, L. E. 1980. A compendium of information about named genes for low reaction to Puccinia recondita in wheat. Crop Sci. 20:775-779.

Brown, J. K., and Hovmøller, M. S. 2002. Aerial dispersal of pathogens on the global and continental scales and its impact on plant disease. Science 297: 537-541.

Casulli, F. 1988. Overseasoning of wheat leaf rust in southern Italy. Pages 166-168 in: B. Zwatz ed. Proceedings of the Seventh European and Mediterranean Cereal Rusts Conference. Federal Institute of Plant Protection, Vienna, Austria.

Casulli, F., and Siniscalco, A. 1987. Thalictrum flavum L. as an alternate host of Puccinia recondita f. sp. tritici in Southern Italy. Proceedings of the Seventh Congress of the Mediterranean Phytopathology Union, Granada, Spain.

Cuomo, C. A., Bakkeren, G., Khalil, H. B., Panwar, V., Joly, D., Linning, R., Sakthikumar, S., Song, X., Adiconis, X., Fan, L., Goldberg, J. M., Levin, J. Z., Young S., Zeng, Q., Anikster, Y., Bruce, M., Wang, M., Yin, C., McCallum, B., Szabo, L. J., Hulbert, S., Chen, X., and Fellers, J. P. 2017. Comparative analysis highlights variable genome content of wheat rusts and divergence of the mating loci. G3 Genes Genomes Genet. 7:361-376.

Duan, X., Enjalbert, J., Vautrin, D., Solignac, C., and Girau, T. 2003. Isolation of 12 microsatellite loci, using an enrichment protocol, in the phytopathogenic fungus Puccinia triticina. Mol. Ecol. Notes 3:65-67.

Eticha, F., Belay, G., and Bekele, E. 2006. Species diversity in wheat landrace populations from two regions of Ethiopia. Genet. Resour. Crop Evol. 53: 387-393.
Feldman, M. W. 2001. Origin of cultivated wheat. Pages 3-58 in: The World Wheat Book: A History of Wheat Breeding. A. Bonjean and W. Angus, eds. Lavoisier, Paris, France.

Germán, S. E., Barcellos, A., Chaves, M., Kohli, M., Campos, P., and de Viedma, L. 2007. The situation of common wheat rusts in the Southern Cone of America and perspectives for control. Aust. J. Agric. Res. 58: 620-630.

Gladieux, P., Fuerty, A., Hood, M. E., Snirc, A., Clavel, J., Dutech, C., Roy, M., and Giraud, T. 2015. The population biology of fungal invasions. Mol. Ecol. 24:1969-1986.

Goyeau, H., Berder, J., Czerepak, C., Gautier, A., Lanen, C., and Lannou, C. 2011. Low diversity and fast evolution in the population of Puccinia triticina causing durum wheat leaf rust in France from 1999 to 2009, as revealed by an adapted differential set. Plant Pathol. 61:761-772.

Goyeau, H., Park, R., Schaeffer, B., and Lannou, C. 2006. Distribution of pathotypes with regard to host cultivars and French wheat leaf rust populations. Phytopathology 96:264-273.

Halkett, F., Simon, J. C., and Balloux, F. 2005. Tackling the population genetics of clonal and partially clonal organisms. Trends Ecol. Evol. 20: 194-201.

Herrera-Foessel, S. A., Huerta-Espino, J., Calvo-Salazar, V., Lan, C. X., and Singh, R. P. 2014. $\operatorname{Lr} 72$ confers resistance to leaf rust in durum wheat cultivar Atil C2000. Plant Dis. 98:631-635.

Hovmøller, M. S., Sorensen, C. K., Walker, S., and Justesen, A. F. 2011. Diversity of Puccinia striiformis on cereals and grasses. Annu. Rev. Phytopathol. 49:197-217.

Hovmøller, M. S., Yahyaoui, A. H., Milus, E. A., and Justesen, A. F. 2008. Rapid global spread of two aggressive strains of a wheat rust fungus. Mol. Ecol. 17:3818-3826.

International Maize and Wheat Improvement Center. 2015. Wheat AtlasEthiopia: Wheat Production and Use. http://wheatatlas.org/varieties

Jin, Y., Szabo, L. J., Rouse, M. N., Fetch, T., Pretorius, Z. A., Wanyera, R., and $\mathrm{Njau}, \mathrm{P}$. 2009. Detection of virulence to resistance gene $\operatorname{Sr} 36$ within the TTKS lineage of Puccinia graminis f. sp. tritici. Plant Dis. 93: 367-370.

Jin, Y., Szabo, L. S., Pretorius, Z. A., Singh, R. P., Ward, R., and Fetch, T. 2008. Detection of virulence to resistance gene $\operatorname{Sr} 24$ within race TTKS of Puccinia graminis. Plant Dis. 92:923-926.

Kamvar, Z. N., Tabima, J. F., and Grünwald, N. J. 2014. Poppr: An R package for genetic analysis of populations with clonal, partially clonal, and/or sexual reproduction. PeerJ 2:e281.

Kolmer, J. A. 1991. Evolution of distinct populations of Puccinia recondita $\mathrm{f}$. sp. tritici in Canada. Phytopathology 81:316-322.

Kolmer, J. A. 1998. Physiologic specialization of Puccinia recondita f. sp. tritici in Canada in 1996. Can. J. Plant Pathol. 20:176-181.

Kolmer, J. A. 2005. Tracking wheat rust on a continental scale. Curr. Opin. Plant Biol. 8:441-449.

Kolmer, J. A. 2015. Collections of Puccina triticina in different provinces of China are related for virulence and molecular genotype. Phytopathology 105:700-706.

Kolmer, J. A., and Acevedo, M. A. 2016. Genetically divergent types of the wheat leaf rust fungus Puccinia triticina in Ethiopia, a center of tetraploid wheat diversity. Phytopathology 106:380-385.

Kolmer, J. A., Hanzalova, A., Goyeau, H., Bayles, R., and Morgounov, A. 2012. Genetic differentiation of the wheat leaf rust fungus Puccinia triticina in Europe. Plant Pathol. 62:21-31.

Kolmer, J. A., and Hughes, M. E. 2017. Physiologic specialization of Puccinia triticina on wheat in the United States in 2015. Plant Dis. 107:1496-1506.

Kolmer, J. A., Kabdulova, M. G., Mustafina, M. A., Zhemchuzhina, N. S., and Dubovoy, V. 2015. Russian populations of Puccinia triticina distant regions are not differentiated for virulence and molecular genotype. Plant Pathol. 64:328-336

Kolmer, J. A., Long, D. L., and Hughes, M. E. 2006. Physiologic specialization of Puccinia triticina on wheat in the United States in 2004. Plant Dis. 90:1219-1224

Kolmer, J. A., Mirza, J. I., Imtiaz, M., and Shah, S. J. A. 2017. Genetic differentiation of the wheat leaf rust fungus Puccinia triticina in Pakistan and genetic relationship to other worldwide populations. Phytopathology 107:786-790.

Kolmer, J. A., and Ordoñez, M. E. 2007. Genetic differentiation of Puccinia triticina populations in Central Asia and the Caucasus. Phytopathology 97: 1141-1149.

Kolmer, J. A., Ordoñez, M. E., Manisterski, J., and Anikster, Y. 2011. Genetic differentiation of Puccinia triticina populations in the Middle East and genetic similarity with populations in Central Asia. Phytopathology 101: 870-877.

Kosman, E., Ben-Yehuda, P., and Manisterski, J. 2013. Diversity of virulence phenotypes among annual populations of wheat leaf rust in Israel from 1993 to 2008. Plant Pathol. 63:563-571. 
Liu, M., Rodrigue, N., and Kolmer, J. 2014. Population divergence in the wheat leaf rust fungus Puccinia triticina is correlated with wheat evolution. Heredity 112:443-453.

Long, D. L., and Kolmer, J. A. 1989. A North American system of nomenclature for Puccinia recondita f. sp. tritici. Phytopathology 79: 525-529.

Long, D. L., Leonard, K. J., and Hughes, M. E. 2000. Virulence of Puccinia triticina on wheat in the United States from 1996 to 1998. Plant Dis. 84: 1334-1341.

Markell, S. G., and Milus, E. A. 2008. Emergence of a novel population of Puccinia striiformis f. sp. tritici in eastern United States. Phytopathology 98:632-639.

McAlpine, D. 1895. Systematic Arrangement of Australian Fungi. Department of Agriculture, Victoria, Melbourne, Australia.

McCallum, B. D., and Seto-Goh, P. 2006. Physiologic specialization of Puccinia triticina, the causal agent of wheat leaf rust, in Canada in 2004. Can. J. Plant Pathol. 28:566-576.

McIntosh, R. A., Dubcovsky, J., Rogers, J., Morris, C., and Xia, X. C. 2017. Catalogue of Gene Symbols for Wheat: 2017 Supplement. Komugi Wheat Genetic Resources Database, Yokohama, Japan. https://shigen.nig.ac.jp/ wheat/komugi/genes/macgene/supplement2017.pdf

McIntosh, R. A., Wellings, C. R., and Park, R. F. 1995. Wheat Rusts: An Atlas of Resistance Genes. Kluwer Academic Publishers, Dordrecht, The Netherlands.

Meirmans, P. G., and van Tienderen, P. H. 2004. GENOTYPE and GENODIVE: Two programs for the analysis of genetic diversity of asexual organisms. Mol. Ecol. Notes 4:792-794.

Ordoñez, M. E., Germán, S. E., and Kolmer, J. A. 2010. Genetic differentiation within the Puccinia triticina population in South America and comparison with the North American population suggests common ancestry and intercontinental migration. Phytopathology 100:376-383.

Ordoñez, M. E., and Kolmer, J. A. 2007a. Simple sequence repeat diversity of a world-wide collection of Puccinia triticina from durum wheat. Phytopathology 97:574-583.

Ordoñez, M. E., and Kolmer, J. A. 2007b. Virulence phenotypes of a worldwide collection of Puccinia triticina from durum wheat. Phytopathology 97:344-351

Ordoñez, M. E., and Kolmer, J. A. 2009. Differentiation of molecular genotypes and virulence phenotypes of Puccinia triticina from common wheat in North America. Phytopathology 99:750-758.

Paradis, E., Claud, J., and Strimmer, K. 2004. APE: Analysis of phylogenetics and evolution in R language. Bioinformatics 20:289-290.

Park, R. F., Burdon, J. J., and McIntosh, R. A. 1995. Studies in the origin, spread, and evolution of an important group of Puccinia recondita $\mathrm{f}$. $\mathrm{sp}$. tritici pathotypes in Australasia. Eur. J. Plant Pathol. 101:613-622.

Peakall, R., and Smouse, P. E. 2012. GenAlex 6: Genetic analysis in Excel. Population genetic software for teaching and research: An update. Bioinformatics 28:2537-2539.

Pole Evans, I. B. 1911. South African cereal rusts, with observations on the problem of breeding rust-resistant wheats. J. Agric. Sci. 4:95-104.

Pretorius, Z. A., Boshoff, W. H. P., and Kema, G. H. J. 1997. First report of Puccinia striiformis f. sp. tritici on wheat in South Africa. Plant Dis. $81: 424$.

Pritchard, J. K., Stephans, M., and Donnelly, P. 2000. Inference of population structure using multilocus genotype data. Genetics 155:945-959.
Roelfs, A. P. 1989. Epidemiology of the cereal rusts in North America. Can. J. Plant Pathol. 11:86-90.

Roelfs, A. P., and Groth, J. V. 1980. A comparison of virulence phenotypes in wheat stem rust populations reproducing sexually and asexually. Phytopathology 70:855-862.

Roelfs, A. P., Singh, R. P., and Saari, E. E. 1992. Rust Diseases of Wheat: Concepts and Methods of Disease Management. International Maize and Wheat Improvement Center, El Batán, Mexico.

Saari, E. E., and Prescott, J. M. 1985. World distribution in relation to economic losses. Pages 259-298 in: The Cereal Rusts, Vol. II, Diseases, Distribution, Epidemiology, and Control. A. P. Roelfs and W. R. Bushnell, eds. Academic Press, Orlando, FL.

Salamini, F., Ozkan, H., Brandolini, A., Schafer-Pregl, R., and Martin, W. 2002. Genetics and geography of wild cereal domestication in the Near East. Nat. Rev. Genet. 3:429-441.

Samborski, D. J. 1985. Wheat leaf rust. Pages 39-59 in: The Cereal Rusts, Vol. II, Diseases, Distribution, Epidemiology, and Control. A. P. Roelfs and W. R. Bushnell, eds. Academic Press, Orlando, FL.

Sibilia, C., Basile, R., and Boskovic, M. 1963. Ricerche sa Thalictrum sp. condotte nei pascoli alpini nel 1962 e 1963. Boll. Stazione Patalogia Vegetale 21:93-97.

Singh, R. P., Huerta-Espino, J., Pfeiffer, W., and Figueroa-Lopez, P. 2004. Occurrence and impact of a new leaf rust race on durum wheat in northwestern Mexico from 2001 to 2003. Plant Dis. 88:703-708.

Steele, K. A., Humphreys, E., Wellings, C. R., and Dickinson, M. J. 2001. Support for a stepwise mutation model for pathogen evolution in Australasian Puccinia striiformis f. sp. tritici by use of molecular markers. Plant Pathol. 50:174-180.

Stenberg, P., Lundmark, M., and Saura, A. 2003. MLGsim: A program for detecting clones using a simulation approach. Mol. Ecol. Notes 3:329-331.

Szabo, L. J., and Kolmer, J. A. 2007. Development of simple sequence repeat markers for the plant pathogenic rust fungus Puccinia triticina. Mol. Ecol. Notes 7:708-710.

Tatlidil, S., Bicakci, A., Malyer, H., and Can Baser, K. H. 2005. Pollen morphology of Thalictrum L. species (Ranunculaceae) in Turkey. Pak. J. Bot. 37:203-212.

Thach, T., Ali, S., deVallavieille-Pope, C., Justesen, A. F., and Hovmøller, M. S. 2016. Worldwide population structure of the wheat rust fungus Puccinia striiformis in the past. Fungal Genet. Biol. 87:1-8.

Tommasi, F., Siniscalco, A., and Paradies, M. 1980. Aecia of an unidentified rust on Thalictrum flavum L. in southern Italy. Pages 191-198 in: Proceedings of the Fifth European and Mediterranean Cereal Rusts Conference, Instituto di Patologia Vegetale, Bari, Italy.

Visser, B., Meyer, M., Park, R. F., Gilligan, C., Burgin, L., Hort, M. C., Hodson, D., and Pretorius, Z. A. 2019. Microsatellite analysis and urediniospore movement dispersal simulations support the movement of Puccinia graminis f. sp. tritici from southern Africa to Australia. Phytopathology 109:133-144.

Wanyera, R., Kinyua, M. G., Jin, Y., and Singh, R. P. 2006. The spread of stem rust caused by Puccinia graminis f. sp. tritici, with virulence on Sr31 in wheat in Eastern Africa. Plant Dis. 90:113.

Wellings, C. R., and McIntosh, R. A. 1990. Puccinia striiformis f. sp. tritici in Australasia: Pathogenic changes during the first 10 years. Plant Pathol. 39: 316-325.

Yehuda, P. B., Eilam, T., Manisterski, J., Shimoni, A., and Anikster, Y. 2004. Leaf rust on Aegilops speltoides caused by a new forma specialis of Puccinia triticina. Phytopathology 94:94-101. 